\title{
Dinâmica financeira dos municípios brasileiros
}

\author{
Márcio Marconato ${ }^{1}$ \\ José Luiz Parré 2 \\ Marcio Henrique Coelho 1 \\ 1 Universidade Estadual de Ponta Grossa / Departamento de Economia, Ponta Grossa / PR - Brasil \\ 2 Universidade Estadual de Maringá / Departamento de Economia, Maringá / PR - Brasil
}

O estudo tem como objetivo explorar as ocorrências fiscais dos municípios brasileiros no período 2002 a 2016, analisando a relação entre as receitas, as despesas com pessoal, os estratos de tamanho, os delineamentos da atividade econômica e as riquezas municipais, considerando momentos de contração e de expansão do produto nacional. O procedimento metodológico consistiu na utilização de uma representação de dados em painel, com a aplicação do teste de especificação de Hausman, em que o modelo de efeito fixo, em confronto com o de efeitos aleatórios, se mostrou mais adequado para apuração da relação da variável dependente e das independentes. O cálculo do Quociente do Resultado de Execução Financeira (QREF) mensurou a situação fiscal das unidades federadas e aferiu as relações do QREF com outras variáveis, tais como o perfil de arrecadação, o balanço econômico municipal, a riqueza econômica da localidade, a despesa com pessoal e o tamanho populacional. As repercussões revelaram que as elevadas despesas com pessoal impactam negativamente as apurações dos resultados fiscais, enquanto que, os melhores cômputos do QREF ocorreram em unidades nas quais foram detectados os maiores indicadores de produto interno bruto per capita. Quanto ao nível de atividade econômica, a preponderância financeira dos setores agrícola e de serviços, revelou melhores condições pecuniárias, ressalvando que nos municípios com perfil industrial e classificados como pequenos foram detectados os piores resultados. No desfecho, a crise econômica de 2009 derivou em resultados fiscais ruins, enquanto que a crise política/econômica de 2015 e 2016 transcorreu com respostas orçamentárias mais apropriadas.

Palavras-chave: setor público; análise tributária; execução orçamentária; arrecadação; gasto.

\section{Dinámica financiera de los municipios brasileños}

Este estudio tiene como objetivo explorar los sucesos fiscales de los municipios brasileños en el período 2002 a 2016, analizando la relación entre ingresos, gastos de personal, estratos de tamaño, delineamientos de la actividad económica y riqueza municipal, considerando momentos de contracción y de expansión del producto nacional. El procedimiento metodológico consistió en utilizar una representación de datos en panel, con la aplicación de la prueba de especificación de Hausman, en la que el modelo de efectos fijos, en comparación con el modelo de efectos aleatorios, resultó ser más adecuado para determinar la relación variable dependiente e independiente. El cálculo del índice de resultados de ejecución financiera (QREF) midió la situación fiscal de las unidades federadas y calculó la relación del QREF con otras variables, como el perfil de recaudación, el balance económico municipal, la riqueza económica del municipio, el gasto en personal y el tamaño de la población. Los resultados mostraron que los elevados gastos en personal tienen un impacto negativo en los resultados fiscales, mientras que los mejores cómputos del QREF ocurrieron en unidades donde se detectaron los indicadores más altos del producto interno bruto per cápita. En cuanto al nivel de actividad económica, la preponderancia financiera de los sectores agrícola y de servicios reveló mejores condiciones pecuniarias, destacando que los peores resultados se encontraron en municipios con perfil industrial y clasificados como pequeños. Al final, la crisis económica de 2009 dio lugar a malos resultados fiscales, mientras que la crisis político-económica de 2015 y 2016 transcurrió con respuestas presupuestarias más apropiadas.

Palabras clave: sector público; análisis tributario; ejecución presupuestaria; recaudación; gasto. 


\section{Financial dynamics of Brazilian municipalities}

The study explores the fiscal events of Brazilian municipalities in the period 2002 to 2016, analyzing the relationship between revenues, personnel expenses, size strata, delineations of economic activity, and municipal wealth, considering moments of contraction and national product expansion. The methodology used panel data, with the application of the Hausman specification test, in which the fixed-effect model, in comparison with the randomeffects model, proved to be more suitable for determining the variable relationship dependent and independent. The calculation of the Quotient of the Financial Execution Outcome (QFEO) measured the fiscal situation of the federated units. It measured the relationship of the QFEO with other variables, such as the collection profile, the municipal economic activity, the municipality's economic wealth, the expenditure on personal, and the population size. The s results showed that higher personnel expenses negatively impact tax investigations. The best calculations in the QFEO occurred in units where the highest gross domestic product indicators were detected per capita. As for the level of economic activity, the financial preponderance of the agricultural and service sectors revealed better pecuniary conditions. The worst results were found in municipalities with an industrial profile and classified as small. The economic crisis of 2009 resulted in poor fiscal results, while the political/economic crisis of 2015 and 2016 had more appropriate budget responses.

Keywords: public sector; tax analysis; budget execution; collection; spent.

\section{AGRADECIMENTOS}

O primeiro autor agradece a Coordenação de Aperfeiçoamento de Pessoal de Nível Superior (CAPES) pela bolsa de doutorado recebida durante a execução da pesquisa.

\section{INTRODUÇÃO}

A presença do estado na economia suscita debates acalorados, entre os que asseguram que o mercado é capaz de proporcionar situações de bem-estar generalizadas, com a maximização da utilidade por partes dos agentes econômicos, e os que garantem que as falhas de mercado conduzem a debilidades no tecido social e que somente o poder público é capaz de estabelecer compensações para o atendimento das demandas.

O sistema tributário brasileiro tem como traço a centralização financeira em favor da União, delegando aos Estados e aos municípios as menores parcelas da arrecadação tributária. Numa comparação temporal, a Constituição Federal de 1988 representou um grande avanço na apropriação de recursos por parte dos Estados e dos Municípios, mas para o caso das cidades classificadas como de pequeno porte I e II, a dependência financeira das transferências constitucionais se sobressai (Riani, 2009).

No caso das prefeituras, a estruturação das receitas totais, agrega os repasses da União, dos Estados e o recolhimento próprio. No cômputo das transferências estabelecidas pela norma, a União é responsável pela entrega de 24,5\% do Imposto de Renda (IR) e do Imposto sobre Produtos Industrializados (IPI), através do Fundo de Participação dos Municípios (FPM), de 100\% do imposto de renda retido na fonte (IRRF), cobrados sobre os rendimentos pagos pelos municípios, de suas autarquias e de fundações que instituírem ou manterem, de 50\% do Imposto Territorial Rural (ITR), de 7,25\% da Contribuição de Intervenção no Domínio Econômico (CIDE-combustíveis) e de 70\% do Imposto sobre Movimentações Financeiras sobre o ouro (IOF-ouro). 
Nos Estados a destinação alcança 50\% do Imposto sobre Propriedade de Veículos Automotores (IPVA), 25\% do Imposto sobre Circulação de Mercadorias e Serviços (ICMS) e 2,5\% do Imposto sobre Produtos Industrializados (IPI), transferidos pela União aos Estados, relacionados às exportações ocorridas no território estadual. Os tributos de competência dos Municípios, portanto receitas próprias estão circunscritas ao Imposto sobre Propriedade Territorial Urbana (IPTU), ao Imposto sobre Serviço de Qualquer Natureza (ISSQN) e ao Imposto sobre Bens Intervivos (ITBI).

A descentralização fiscal, considerando as argumentações de Musgrave (1959), tem o potencial de promover melhorias contínuas de bem-estar, sob a premissa de que a proximidade dos gestores públicos com os cidadãos pode levar a uma provisão mais eficiente de bens e serviços ou, no caso de malversação dos recursos públicos, a uma tensão social com impactos políticos eleitorais.

Indiscutivelmente, os efeitos deletérios das pretensões políticas geram consequências ruins para as finanças, pois em cidades com baixo nível de atividades econômicas, pode haver um posicionamento pelo recolhimento mínimo, isto é, os prefeitos evitam o ônus político da cobrança tributária, definindo alíquotas menores e, em algumas circunstâncias, a concessão de perdão de dívidas. Nesses casos, ambicionam o menor atrito possível com os cidadãos, financiando as atividades locais com as transferências constitucionais (Afonso, Araujo \& Nóbrega, 2010). Na hipótese de restrições financeiras, indicam o Governo Federal ou o Governo Estadual, dependendo das alianças políticas, como responsáveis pelas dificuldades operacionais.

Apesar disso, no balanço contábil, o nível de receitas próprias está diretamente relacionado ao grau de atividade econômica, uma vez que em municípios com elevados níveis de produto per capita, há uma tendência de incisiva parcela do recolhimento local na receita total.

Em ato contínuo, a delimitação dos gastos com pessoal e com os encargos das dívidas de curto prazo, representada pelos restos a pagar e consolidadas, inseridas nas despesas correntes, constitui talvez o maior desafio financeiro, em contextos de decisões técnicas, mas afetadas por interesses políticos expressos nas escolhas orçamentárias.

Ao mesmo tempo, as tabulações relativas ao efeito localização e a proximidade geográfica assumem relevância, pois em administrações com maiores níveis de riqueza e de desenvolvimento, as possibilidades de transbordamentos de rendas não estão descartadas, incrementando as economias das cidades menores, com as ressalvas da existência de atributos naturais e de construídos, circunscritos em cenários de influências desiguais sobre as administrações públicas (Quintela, 2011).

Partindo da premissa da existência de discrepâncias regionais, o objetivo da pesquisa é explorar as ocorrências fiscais dos municípios brasileiros no período 2002 a 2016, analisando a relação entre as receitas, as despesas com pessoal, os estratos de tamanho, os delineamentos da atividade econômica e as riquezas municipais, considerando momentos de contração e de expansão do produto nacional.

O estudo, além desta introdução, apresenta outras quatro secções: o referencial empírico, com a apresentação de estudos que sustentam o modelo proposto, por meio de evidências de outros ensaios com abordagens próximas, a metodologia, com a exposição dos principais indicadores utilizados e dos procedimentos metodológicos aplicados, a análise dos resultados, através das revelações e discussões sobre as principais reflexões da pesquisa, intentando compreender e predizer os melhores comportamentos fiscais a serem aplicados pelas municipalidades e as considerações finais. 


\section{REFERENCIAL EMPÍRICO}

Estabelecendo um compêndio sobre o tema no âmbito internacional, merece destaque o estudo desenvolvido por Hansen, Houlberg e Pedersen (2014), no qual foi avaliada a gestão fiscal dos municípios dinamarqueses no período de 2003 a 2011, por meio do emprego da metodologia de painel de dados. Nas cidades de maior porte, ocorreram os melhores resultados, ancorados no fato de que dispunham de maiores receitas tributárias e, em momentos de instabilidade, espaços financeiros e administrativos para remanejamentos.

Outra investigação fiscal, agora nos municípios norte-americanos, foi desenvolvida por $\mathrm{He}$ (2014), que indicou a existência de insolvência de fundos em cidades localizadas em estados com superavit financeiro. Apontou, também, a ocorrência de situações de intervenção de Estados em Municípios, com definições de diretrizes detalhadas para as programações orçamentárias, de financiamentos, de contratações e de reformas administrativas.

Num caso mais específico, Chernick e Reschovsky (2013) concentraram suas pesquisas nos aspectos contábeis da cidade de Milwaukee, a mais populosa do Estado de Wisconsin nos Estados Unidos. Nas mensurações, existiu uma ampla discrepância entre os resultados dos subúrbios componentes do estado, no intervalo de 2009 a 2013. Adicionalmente, examinaram os efeitos negativos da crise de 2008 sobre a cobrança pública em 112 grandes cidades e, do mesmo modo, a existência de associações positivas entre o crescimento populacional e o emprego em localidades com condições fiscais melhores.

Em um contexto peculiar, outros dois estudos abordaram aspectos fiscais na Argentina. O primeiro, de Castilllo (2005), analisou o resultado fazendário das 24 províncias, incluindo a capital federal, no período de 1996 a 2003, com o qual o autor estabeleceu relações econômicas entre os endividamentos e as arrecadações, os juros das dívidas e as despesas correntes, as receitas próprias e os produtos e as razões das taxas do crescimento necessárias para os ajustes fiscais. As circunstâncias indicaram que a melhoria das situações tributárias, sustentáveis no longo prazo, estava interligada ao crescimento do produto.

O segundo ensaio, organizado por Mangas, Accotto e Martínez (2016), investigou as estruturas fiscais nos departamentos da Argentina, ponderando a receita e a despesa, a autonomia financeira, o resultado financeiro, a arrecadação própria e o investimento local público, a aplicação de princípios de homogeneidade na qualidade e na acessibilidade aos bens e aos serviços, em todo o território nacional, poderia representar uma medida de eficiência nas alocações financeiras dos recursos públicos.

No cenário brasileiro, diversos autores abordaram a temática das finanças públicas, com destaques para as análises originadas após a sanção da Lei de Responsabilidade Fiscal (LRF). Considerando as diferenças regionais, Magalhães (2017) avaliou a situação dos municípios brasileiros levando em conta o Índice de Gestão Fiscal (IGF) da Federação das Indústrias do Rio do Janeiro (Firjan), no intervalo 2006 a 2013. Com a utilização do modelo de dados em painel dinâmico, apontou que as ampliações dos gastos com pessoal pioraram os quadros gerenciamento. Comparativamente, os índices financeiros dos Municípios da Região Sul foram os melhores no território nacional, com maiores participações das receitas tributárias e, consequentemente, elevadas participações do produto por habitante.

Contribuindo com a temática, o trabalho de Covre e Mattos (2016) examinou a situação fiscal dos municípios brasileiros no intervalo entre 2006 e 2015, por meio da aplicação de um modelo de dados em painel dinâmico espacial. Os resultados apontaram para um aumento nas despesas com pessoal em unidades com grande interação espacial, com reflexos sobre o equilíbrio financeiro. As 
melhores condições fiscais foram encontradas nas grandes cidades e em locais onde os prefeitos estavam alinhados politicamente com as esferas superiores de poder.

Estabelecendo interligações entre o nível de receitas de um município e de seus vizinhos, Silva e Porsse (2015) utilizaram a regressão ponderada geograficamente para verificar se havia alguma influência na definição das alíquotas dos tributos do IPTU e do ISS, por conta da decisão tomada pelos Municípios próximos. Os quocientes apontaram para a existência de interações estratégicas nas determinações das alíquotas dos dois tributos, bem como a influência negativa das transferências sobre o esforço tributário municipal, com a ressalva de que a relação espacial dos impostos apresentou padrões diferentes na extensão do território nacional.

Com uma visão mais ampla, Reis (2015) relacionou fatores sociais, econômicos, demográficos, o envelhecimento da população, a urbanização, o valor adicionado por setores, o produto per capita e o ciclo eleitoral, como elementos de aferição da qualidade da gestão fiscal. Compreendeu que a melhoria fiscal se associou aos ciclos políticos, com sinal positivo, assegurando que o progresso tributário tende a se manifestar nas unidades com as maiores disponibilidades financeiras.

O resultado fiscal primário dos municípios brasileiros do mesmo modo foi analisado por Sakurai (2014), considerando o horizonte temporal de 1999 a 2007 e a existência do biênio inicial sem o concurso da LRF. Por meio da metodologia de viés de seleção para dados em painel, constatou que as elevadas despesas com pessoal aumentaram o saldo financeiro para o ano seguinte, por conta da inevitabilidade de um ajuste fazendário, via aumento de receitas ou redução de despesas.

De modo mais amplo, além da base de informações da Firjan (2016), Klering, Kruel e Stranz (2012) adicionaram os índices de avaliação da Confederação Nacional de Municípios, para examinar os estratos de pequeno e de grande porte dos Municípios brasileiros no intervalo 2002 a 2009. Constataram que a descentralização da administração pública pode ter contribuído para a geração de melhores índices de gestão nos pequenos Municípios, com a presença de indicadores de desenvolvimento mais robustos.

Em uma análise circunscrita aos municípios paranaenses com menos de cinco mil habitantes, Gerigk e Clemente (2011) notaram que as fronteiras econômicas e jurídicas impostas pela LRF, levaram ao aperfeiçoamento das práticas do planejamento financeiro, por conta da dependência das receitas de transferências e das despesas com pessoal.

Com foco na oferta de serviços, entre os anos de 2002 a 2005, Pinheiro (2009) fez uso de técnicas de estatística multivariada para mostrar a situação fiscal dos municípios. Os efeitos revelam que nas unidades com status de polo e com as maiores ofertas de serviços, a participação relativa das transferências constitucionais foi menor, com tendências de pesos mais expressivos para as captações derivadas do recolhimento próprio. Como exemplo, apontou a concatenação entre a dependência dos repasses federais e a reduzida oferta de serviços nos Municípios da Região Nordeste.

Estabelecendo uma associação entre a qualidade da gestão fiscal e o nível de ajustamento dos entes públicos às demarcações e regras da LRF, limitadas ao período 1998 a 2006, Gobetti e Klering (2007) constataram que nos Municípios com os melhores índices fiscais, existiam médias inferiores aos índices de qualidade de gestão, enfatizando que os superavit maiores estavam associados a menores despesa de capital.

Considerando os princípios da norma jurídica, Fioravante, Pinheiro e Vieira (2006) avaliaram os impactos do limite de gastos com pessoal tendo como parâmetros a demarcação dos $54 \%$, definidos para o Poder Executivo. Constataram que a baliza de gastos imposta pela legislação foi

Revista de Administração PÚblica | Rio de Janeiro 55(2): 378-394, mar. - abr. 2021 
respeitada pela maioria das unidades e que os desvios, as extrapolações, haviam sido combatidos com ajustes financeiros imediatos, monitorados pelos respectivos tribunais de contas, fato esse fundamental para o êxito.

A cobrança tributária e as dificuldades de execução por parte dos gestores compuseram o centro da pesquisa de Tristão (2003). Analisando o período que antecedeu a vigência da LRF, 1998 a 2000, o autor tabulou 4.617 unidades e empregou a técnica de cluster. Os resultados revelaram que as receitas tributárias municipais apresentaram crescimentos constantes e superiores aos percebidos pela União e pelos Estados, explicados pelos incrementos nos repasses constitucionais. No último ano de exame, por exemplo, do total arrecadado pela União, aproximadamente $16,9 \%$ foram destinadas aos Municípios.

Os estudos apresentados reforçam, guardadas as devidas características regionais do Brasil, o federalismo e as questões orçamentárias que se manifestam nas vinculações das receitas, que os perfis socioeconômicos, as condições demográficas, o volume de riqueza e os avanços na gestão, interferem sobre maneira na dinâmica fiscal dos municípios. Sob a perspectiva política, a compatibilidade de interesses entre os prefeitos e as outras esferas do Executivo, pode favorecer os resultados fiscais, uma vez que a agilidade e a regularidade financeira favorecem o planejamento, mesmo em contextos de grandes diversidades regionais e inconstâncias econômicas e políticas.

\section{METODOLOGIA}

\subsection{Aspectos gerais}

A investigação contempla a análise fiscal dos Municípios brasileiros sob vigência da LRF, aprovada no ano 2000, ao abrigo de novas práticas de planejamento, com transparência, fiscalização e responsabilização. O período investigado, de 2002 a 2016, abarca: tempos de instabilidade macroeconômica e de baixo crescimento do produto, tal como em 2003 a 2005; de crescimento nas receitas tributárias, como em 2007; de desconfianças nos retornos financeiros, como na crise internacional de 2008; e de incertezas políticas internas, do modo como ocorreu em 2015 e 2016, com impactos distintos na arrecadação pública, isto é, com tendência de alta entre 2002 a 2008 e de baixa no intervalo 2009 a 2016.

Como fontes de dados foram utilizadas as informações da Secretária do Tesouro Nacional (STN), dados contábeis dos Municípios no item Finanças do Brasil (FINBRA), e do Instituto Brasileiro de Geografia e Estatística (IBGE), por meio do tópico Municípios.

A eficiência na execução das ações planejadas pelos gestores públicos, na visão de Lima e Castro (2000), pode ocorrer por meio da investigação dos balanços orçamentários, que também permitem a prospecção de elementos para definição dos caminhos que serão trilhados.

Para consecução do objetivo proposto, a aplicação do Quociente do Resultado de Execução Financeira (QREF), apresentado por Kohama (1999), representa um mecanismo de acompanhamento do resultado fiscal primário, calculado com base no produto da divisão do somatório da receita total (que engloba a receita orçamentária e extraorçamentária) pela despesa total (que inclui a despesa orçamentária e extraorçamentária). Assim:

$$
\mathrm{QREF}=\text { receita total / despesa total }
$$


Desse modo, o equilíbrio fiscal nas contas de um Município ocorre quando o montante da receita equivale ao montante da despesa, enquanto que o superavit fiscal acontece com o QREF maior que 1 e o deficit com o QREF menor que 1, num determinado período de tempo. Nos estudos de Lima e Castro (2000) e de Silva et al. (2013), houve o emprego do QREF, cabendo ressaltar que no trabalho de 2013 a análise abrangeu os resultados do Governo Federal.

$\mathrm{Na}$ apuração das variáveis explicativas, foram selecionados elementos da receita, com a triagem da arrecadação própria, os repasses dos Estados e da União, da despesa, com a mensuração do gasto com pessoal, da atividade econômica, com a fatia da indústria, dos serviços e da agricultura no PIB municipal, da riqueza econômica, estimada pelo PIB per capita e do porte dos Municípios.

Sob o ângulo das receitas, a utilização do Indicador de Receita Própria (IRP) possui como objetivo demonstrar a capacidade de recolhimento do Município a partir do recolhimento do IPTU, do ITBI, do ISSQN, das taxas e contribuições de melhorias. O parâmetro terá como elementos a divisão da receita própria pela receita total. O emprego do critério tem como base as aplicações de Magalhães (2017), Crove e Mattos (2016), Sakurai (2014) e Gerigk e Clemente (2011).

Sequencialmente, o Indicador de Receita do Governo Estadual (IRGE) contém o propósito de demonstrar o quanto dos impostos entregues pelos Governos Estaduais representa na receita total. O trabalho de Magalhães (2017) considerou os repasses dos entes federados sobre a receita total como uma forma de mensurar se essas transferências impactavam no equilíbrio fiscal.

Por conseguinte, o Indicador de Receita do Governo Federal (IRGF), tem por fim, verificar a parcela do repasse União na formação da receita total. Igualmente, os estudos de Magalhães (2017) e de Tristão (2003) também consideraram a participação dessa fonte de arrecadação na explicação do peso das transferências da administração central nos quantitativos dos recebimentos municipais.

Entretanto, é preciso raciocinar que os indicadores de receita têm como foco a caracterização dos perfis de recolhimento dos municípios brasileiros, não sendo possível a priori definir o sinal a ser encontrado no produto do modelo.

Sob a ótica das despesas, o Indicador de Gasto com Pessoal (IGP) tem por finalidade verificar o quanto os Municípios direcionam para o pagamento de funcionários, diante da Receita Corrente Líquida $(\mathrm{RCL})^{1}$. Os desembolsos da rubrica serão divididos pela RCL. A relação deve ser negativa entre o gasto com pessoal e o QREF. Cabe salientar, que os gastos com pagamento dos servidores públicos tem se configurado num desafio para os prefeitos, pois representam despesas que não podem ser reduzidas facilmente, considerando o princípio da irredutibilidade dos salários, o que pode afetar o equilíbrio fiscal (Covre \& Mattos, 2016; Fioravante et al., 2006; Magalhães, 2017; Sakurai, 2014).

Sob a perspectiva da atividade econômica, a fatia da indústria no PIB municipal (PARTI) busca verificar a atuação da manufatura no produto, pois a cobrança está diretamente associada ao funcionamento da economia, considerando que a velocidade e a magnitude guardam particularidades nos diferentes setores e regiões. O valor agregado da indústria será dividido pelo PIB, guardando o pressuposto que nas cidades mais industrializadas, as condições fiscais serão melhores. Cabe frisar que a utilização desse indicador na verificação dos impactos sobre a recolhimento tributário, IPTU e ISSQN, foi utilizada também por Silva e Porsse (2015).

\footnotetext{
${ }^{1}$ A receita corrente líquida (RCL) é calculada, segundo o SNT (2017), deduzindo-se da receita corrente as receitas de contribuições sociais e as deduções do FUNDEB.
} 
Da mesma forma, a participação da agricultura (PARTA) possui como meta aferir a fração da atividade econômica no total. O cálculo da variável considera a divisão do valor agregado bruto da agricultura pelo valor agregado bruto total, multiplicado por 100 .

A parcela da agricultura no PIB brasileiro vem se mantendo estável desde 2002, conforme dados do IBGE (2017), mas como os Municípios apresentam características peculiares no âmbito econômico, não é possível considerar uma hipótese inicial quanto a relação da atividade agrícola e do resultado fiscal.

Com natureza semelhante, a estimação do setor de serviços (PARTS) incorpora a intenção de refletir com que intensidade o segmento contribuiu para a formação do PIB. No cômputo dos montantes, o valor agregado será dividido pelo valor adicionado bruto e multiplicado por 100 . O grande peso dos serviços nas principais economias do mundo leva à suposição inicial de que quanto maior for a sua participação, melhor será a apuração monetária.

Ainda, considerando na atividade econômica o PIB per capita (PIBPC), o qual tem como proposta verificar se os Municípios mais ricos ostentam melhores condições fiscais, haja vista que a arrecadação própria por exemplo, depende do poder econômico da população e das decisões políticas. No entendimento de alguns autores, entre os quais Magalhães (2017), Reis (2015) e Castillo (2005) as localidades com os maiores níveis de atividades econômicas, tendem a apresentar melhores resultados pecuniários, uma vez que conseguem gerar maiores volumes de receitas próprias.

Pontualmente, a variável população (POP) reúne o quantitativo populacional das cidades, contextualizando se o tamanho do município pode influenciar na situação fiscal. Autores como Magalhães (2017), Crove e Mattos (2016) e Sakurai (2014) consideraram o tamanho populacional em seus estudos e encontraram evidências a favor dos Municípios maiores no que se refere as condições monetárias.

\subsection{Procedimentos metodológicos}

Os modelos de regressão com dados em painel combinam elementos em série temporal e observações em corte transversal multiplicadas por T períodos no tempo. Nesses casos, há mais informações para esclarecer o fenômeno estudado, com graus de liberdade adicionais. Como destaques, os trabalhos de Baltagi (2001) e de Hsiao (2003) indicam algumas vantagens da utilização dos dados em painel em relação ao uso específico do corte transversal ou das séries temporais.

\section{- Modelo de efeitos fixos}

O modelo de efeitos fixos permite o controle dos resultados das variáveis omitidas que variam entre indivíduos e permanecem constantes ao longo do tempo. Entretanto, parte da premissa que o intercepto varia de um indivíduo para o outro, mais é constante ao longo do tempo, ao passo que os parâmetros respostas são constantes para todos os indivíduos e em todos os períodos (Hill, Griffiths \& Judge, 1999). A representação do painel com efeitos fixos leva em conta:

$$
y_{t}=\alpha+\beta X_{t}+\varepsilon_{t}
$$

em que: $\alpha=\left(\alpha_{1}, \ldots, \alpha_{n}\right)$ representa o vetor que denota os efeitos fixos, ou seja, termos de intercepto não observados, específicos a cada região e constantes ao longo do tempo de análise; $y_{t}$ a variável 
dependente; $X_{t}$ as variáveis exógenas; $\beta$ o vetor dos coeficientes das variáveis explicativas; e $\varepsilon_{t}$ o termo de erro que se supõe ser idêntico e independentemente distribuído (iid) com média zero e variância constante.

\section{- Modelo de efeitos aleatórios}

O modelo de efeitos aleatórios pressupõe que o intercepto (aleatório) de uma unidade individual não está correlacionado com as variáveis explicativas (Wooldridge, 2002), definido da seguinte forma:

$$
\begin{gathered}
y_{t}=\beta X_{t}+\varepsilon_{t} \\
\varepsilon_{t}=\alpha+\xi_{t}
\end{gathered}
$$

A estrutura é circunstanciada para o processo de erro, também conhecido como modelo de componente de erro, incluindo agora o componente $\alpha$ dentro da estrutura de erro, em que $\alpha \sim(0$, $\sigma_{\alpha}^{2}$ ) designa um componente de erro aleatório, variando através das regiões, embora seja constante ao longo do tempo.

\section{- Procedimento para escolha e validação do modelo de painel}

O primeiro passo é estimar o modelo em painel com efeitos fixos e aleatórios e na sequência utilizar o Teste de Hausman, para escolher entre os modelos. A validação do modelo mais adequado deve ser feita por meio das seguintes condições: na verificação da homoscedasticidade, que equivale a supor que não existem observações incluídas na variável residual, o Teste de Wald considera a hipótese nula em que há ausência de heterocedasticidade; no teste de ausência de autocorrelação, neste estudo, será empregado o Teste de Wooldridge, cuja hipótese nula é a ausência de correlação. Com a indicação de autocorrelação e/ou heterocedasticidade, a correção terá como base a estimação do modelo considerando os erros-padrão robustos.

\section{- Modelo em painel a ser estimado}

O modelo em painel convencional a ser estimado apresenta a seguinte especificação de acordo com a equação:

$$
\begin{gathered}
\text { LNQREF }_{i t}=\alpha+\beta_{1}(\text { LNIRP })_{i t}+\beta_{2}(\text { LNIRGE })_{i t}+\beta_{3}(\text { LNIRGF })_{i t}+\beta_{4}(L N I D P)_{i t}+\beta_{5}(\text { LNPARTA })_{i t}+ \\
\beta_{6}(\text { LNPARTI })_{i t}+\beta_{7}(\text { LNPARTS })_{i t}+\beta_{8}(\text { LNPIBPC })_{i t}+\beta_{9}(L N P O P)_{i t}+\varepsilon_{i t}
\end{gathered}
$$

em que: $\mathrm{i}=$ representa os municípios e $\mathrm{t}=15$ anos (2002 a 2016), sendo que $\alpha$ refere-se ao intercepto; e $\beta_{1}(\ldots), \beta_{9}$ são parâmetros a serem estimados e representam as variáveis explicativas do modelo; e $\varepsilon_{i t}$ o termo erro. A aplicação do logaritmo natural será considerada para harmonização entre as variáveis explicativas e o QREF.

Nesse contexto, o estudo está centrado em um painel desbalanceado, pois nos anos de 2012 houve o registro de um número menor de Municípios equivalente a 4.379 unidades, e no ano de 2015, o maior número totalizando 5.217 unidades. 


\section{ANÁLISE DOS RESULTADOS}

Confrontando os resultados obtidos pela análise das estatísticas descritivas, foi observado que a média do QREF ficou em 1,06, com valores mínimos e máximos de 0,21 e 1,90, respectivamente. As receitas próprias participaram com aproximadamente $6,41 \%$, com um mínimo de $0,06 \%$ e um máximo de 49,76\%. Com relação aos repasses, a média de presença do Estado foi de 21,93\%, com extremos de $0,23 \%$ e a $74,91 \%$, enquanto que no caso da União foi de $49,15 \%$, com o menor valor de $2,84 \%$ e o maior de 75,00\%. Na identificação dos gastos com pessoal, o percentual médio foi de 48,53\%, com limites entre $20,01 \%$ e 74,50\% (Tabela 1 ).

Nas ponderações sobre o perfil econômico dos Municípios, a indústria apresentou a menor cooperação média, com 14,41\% do produto nos Municípios, com fronteiras de 0,19\% e 96,87\%. $\mathrm{Na}$ agricultura, o valor médio atingiu $22,36 \%$ da riqueza gerada nos municípios, com demarcações mínimas de $0,19 \%$ e máximas de $90,77 \%$. Os serviços exibiram o maior peso relativo médio com $63,21 \%$ do PIB e proporcionais inferiores de 2,05\% e superiores de 98,30\% (Tabela 1).

O contingente populacional médio foi de quase 33 mil habitantes, com um mínimo de 807 pessoas e um máximo de 11 milhões de cidadãos, ao passo que as mensurações do PIBPC atingiram perto de $\mathrm{R} \$ 13$ mil, com o menor indicando R \$4,5 mil e o maior próximo de $\mathrm{R} \$ 388$ mil (Tabela 1).

\section{TABELA 1 ESTATÍSTICAS DESCRITIVAS DAS VARIÁVEIS}

\begin{tabular}{lccccc}
\hline Variáveis & OBS & Média & Desvio-Padrão & Mínimo & Máximo \\
\hline QREF & 70.622 & 1,06 & 0,11 & 0,21 & 1,90 \\
\hline IRP & 70.622 & 6,41 & 5,89 & 0,06 & 49,76 \\
IRGE & 70.622 & 21,93 & 11,68 & 0,23 & 74,91 \\
IRGF & 70.622 & 49,15 & 11,13 & 2,84 & 75,00 \\
IDP & 70.622 & 48,53 & 8,78 & 0,25 & 74,50 \\
PARTI & 70.622 & 14,41 & 15,00 & 0,19 & 96,87 \\
PARTA & 70.622 & 22,36 & 16,11 & 0,01 & 90,77 \\
PARTS & 70.622 & 63,21 & 16,57 & 2,05 & 98,30 \\
POP & 70.622 & $32.831,97$ & $144.385,60$ & 807 & 12.038 .175 \\
PIBPC (R\$) & 70.622 & $12.761,48$ & $14.824,36$ & $4.533,95$ & $377.985,30$ \\
\hline
\end{tabular}

Fonte: Elaborada pelos autores.

A constatação do melhor modelo para averiguar a relação entre o QREF com as variáveis explicativas foi realizada através do Teste de Hausman. Num primeiro momento, ocorreu a estimação dos modelos de efeitos fixos e aleatórios e em seguida a aplicação do teste. O resultado indicou o modelo de efeitos fixos como o mais apropriado (Tabela 2).

Assim, as análises dos coeficientes foram submetidas ao Teste de Wald, com o intuito de constatar se o modelo de efeitos fixos apresentava ou não heterocedasticidade. A significância estatística do 
teste confirmou a existência do problema. Da mesma forma, a significância estatística obtida com a aplicação do Teste de Woodridge revelou a existência de autocorrelação. A solução para os problemas, foi obtida com a estimação considerando o erro-padrão robusto de White, a fim de minimizar os possíveis impactos negativos sobre os resultados (Tabela 2).

TABELA 2 TESTE DE ESPECIFICAÇÃO DO MODELO E DIAGNÓSTICO DA REGRESSÃO

$\begin{array}{ccc} & \text { Teste de Especificação do Modelo } & \\ \text { Resumo do teste } & \text { Teste de Hausman } & \text { Probabilidade } \\ \text { Diagnóstico da Regressão para Autocorrelação no Modelo de Efeitos Fixos } & 0,000 \\ & 3.962,13 & \text { Probabilidade } \\ \text { Resumo do teste } & \text { Teste de Woodridge } & 0,000 \\ \text { Diagnóstico da Regressão para Heterocedasticidade no Modelo de Efeitos Fixos } & \text { Probabilidade } \\ & \text { Teste de Wald } & 0,000\end{array}$

Fonte: Elaborada pelos autores.

Com o intuito de melhorar a compreensão dos impactos das diversas variáveis sobre o resultado fiscal dos Municípios brasileiros, foram feitas as estimações da representação econométrica de dados em painel modelo fixo, para o período de 2002 a 2016.

Os resultados indicaram que as receitas derivadas do IRP, IRGF, IRGE estão relacionadas com o QREF. Da mesma forma, o perfil das atividades econômicas revelou que existem correspondências entre os setores industrial, agrícola e de serviços e o QREF (Tabela 3).

As despesas com pessoal foram incluídas no modelo, diante dos impactos negativos do excesso de gastos com a folha nos resultados agregados, em conjunto com as informações do PIBPC dos municípios, para aferição da riqueza, com o intuito de analisar as suas relações com o QREF.

Um ponto extremamente relevante na investigação, a estratificação da grandeza populacional dos municípios possibilitou a análise do porte perante os resultados fiscais, com a inclusão de uma variável do tamanho populacional. A variável dummy ano captou o comportamento do QREF durante os períodos em que a economia brasileira vivenciou quedas do produto, ou melhor, em 2009, 2015 e 2016. 


\section{TABELA 3 RESULTADO DO MODELO EM PAINEL COM EFEITOS FIXOS PARA OS MUNICÍPIOS BRASILEIROS / VARIÁVEL DEPENDENTE: LNQREF}

\begin{tabular}{lcc}
\hline Variáveis & \multicolumn{2}{c}{ Modelo de Efeitos Fixos (Erro Robusto) } \\
\hline CONSTANTE & Coeficientes & Erro-padrão \\
\hline LNIRP & $-0,6103^{*}$ & 0,0637 \\
\hline LNIRGF & $-0,0245^{\star}$ & 0,0012 \\
LNIRGE & $-0,1339^{\star}$ & 0,0052 \\
LNIDP & $-0,0428^{*}$ & 0,0026 \\
LNPARTA & $-0,1552^{*}$ & 0,0039 \\
LNPARTI & $0,0206^{*}$ & 0,0016 \\
LNPARTS & $-0,0043^{*}$ & 0,0013 \\
LNPIBPC & $0,1008^{*}$ & 0,0040 \\
LNPOP & $0,0866^{*}$ & 0,0014 \\
DUMMY09 & $0,0728^{*}$ & 0,0053 \\
DUMMY15 & $-0,0250^{*}$ & 0,0010 \\
DUMMY16 & $0,0774^{*}$ & 0,0011 \\
\hline observação: *Significativo a $1 \%$. & $0,0545^{*}$ & 0,0012 \\
Fonte: Elaborada pelos autores. & & \\
\hline
\end{tabular}

A caracterização das receitas revela o perfil arrecadador dos Municípios, indicando quanto os prefeitos dispunham de recursos próprios, do Governo Federal e dos Governos Estaduais, para fazer frente às despesas. Os coeficientes do IRP, IRGF e do IRGE apresentaram sinais negativos e significativos. Nesse sentido, a compreensão é de que o sinal negativo observado para os indicadores de receita revela que, independentemente de onde vêm as receitas, a gestão dos recursos e a contenção dos gastos influência mais os resultados. Assim, um Município pode arrecadar mais via receita própria e outro pode obter mais recursos, mediante os repasses do Governo Federal, sendo que ambos podem apresentar um QREF igual a 1 (equilíbrio fiscal) ou superior a 1 (superavit fiscal).

Nesse contexto, a eficiência na gestão do recurso público se configura em grande desafio para os prefeitos que estimam o orçamento de um ano para outro, e vão obtendo os recursos mensalmente, com valores maiores ou menores, a depender da conjuntura econômica. O estudo realizado pela Firjan em 2016 revelou por meio do Índice de Gestão Fiscal (IFGF), que 36,3\% das prefeituras estão em situação crítica, $51,1 \%$ em dificuldades, $12,1 \%$ em gestão boa e somente $0,5 \%$ (23 prefeituras) obtiveram conceito de excelência na gestão, mesmo com os programas de ajuste do pós-Real e da LRF (Firjan, 2016).

Os resultados ainda apontam para um alinhamento entre as evidências mencionadas por Sakurai (2014), ao analisar os saldos tributários, o autor não encontrou impactos significativos das participações das receitas próprias sobre as situações fiscais dos Municípios. Concluiu que a arrecadação proveniente 
dos tributos municipais foi residual, quando comparada com os valores totais, fato que poderia explicar as evidências encontradas no estudo.

Sobre o perfil de arrecadação observado nos municípios brasileiros, Afonso e Araújo (2000), reiteram que após a Constituição Federal de 1988, houve um forte incremento no recolhimento próprio dos Municípios, decorrentes do novo pacto federativo. Entretanto, ainda é visível que as transferências constitucionais compõem grande parte da receita corrente total, quando comparados com os percentuais auferidos com os recursos provenientes das cobranças tributárias, no caso dos Municípios de pequeno porte.

As tabulações das despesas com pessoal (IDP) indicaram a presença de sinal negativo, revelando que um aumento dos gastos com a folha de pagamento pode comprometer as contas Municipais, potencializando problemas de caixa. Outros estudos, a exemplo de Fioravante et al. (2006) e Magalhães (2017), também demonstraram esse fato, sustentados na premissa de que aumentos de salários e de contratações sem planejamento orçamentário resultam em maiores destinações de recursos financeiros, comprometendo os resultados fiscais. Na maioria dos casos, a legislação não permite a redução de salários, ficando essa opção fora do rol das escolhas para a contração desse tipo de despesa.

Entre os setores econômicos, os três apresentaram significância a 1\%. Nas unidades com predominância da indústria (PARTI), o QREF foi menor, conforme corroborado pela existência do sinal negativo, isso pode ser reflexo da baixa participação da indústria nos pequenos municípios que estão em maior número na amostra.

Diferentemente, nos municípios em que a porção da agricultura (PARTA) e do setor de serviços (PARTS) foi preponderante, foram verificados maiores valores para o QREF. Essas evidências são relevantes, pois inicialmente o esperado era que o perfil econômico voltado à indústria contribuísse positivamente para melhorar os indicadores fiscais. No estudo desenvolvido por Silva e Porsse (2015), foram encontradas situações nas quais os municípios mais industrializados, apresentaram maiores arrecadações com o IPTU e com o ISSQN, reforçando a importância desse setor para o caixa das prefeituras.

Nas mensurações do coeficiente do PIBPC, sobreveio um sinal positivo e com significância, conforme o esperado, revelando que os Municípios mais ricos tendem a apresentar melhores condições, uma vez que o dinamismo econômico tem impactos sobre a renda, o consumo e a riqueza, as principais fontes de arrecadação, tanto na esfera das receitas próprias, quanto nas das transferências correntes. Outros estudos, como Magalhães (2017) e Castillo (2005), confirmam as mesmas evidências quanto aos impactos do PIB sobre gestão fiscal.

Nesse sentido, a adoção de políticas macroeconômicas que visem o crescimento, com a recuperação dos salários, simplificação para o funcionamento de empresas e acesso a novas tecnologias, pode contribuir para o aumento na oferta de produtos regionais, com efeitos positivos sobre as arrecadações.

O sinal positivo da variável população indicou que quanto maior for o porte do Município, mais elevado será o indicador do QREF, no nível de significância de 1\%. Essa percepção foi encontrada nos estudos de Crove e Mattos (2016), nos quais foram constatadas melhores condições fiscais nos Municípios maiores. Isso impõe a necessidade de se refletir sobre três pontos: a reorganização da estrutura tributária, o impedimento para a criação de novos municípios e a atenção especial para com as finanças das pequenas cidades que não conseguem gerenciar seus recursos financeiros, gerando desdobramentos negativos sobre a organização dos serviços públicos. 
O comportamento das variáveis nos anos de 2009, 2015 e 2016, momentos de crise econômica, indicou uma variação real negativa do PIB nacional, com sinal dos coeficientes negativos para o ano de 2009, apontando que em comparação com as demais épocas; o QREF foi menor, reforçando os efeitos dos impactos derivados da instabilidade iniciada em 2008 na economia norte-americana. Sob outra perspectiva, nos anos de 2015 e de 2016 os resultados foram positivos, revelando cenários melhores para os quocientes fiscais, o que evidenciou uma contradição, pois em tempos de redução do PIB, em ato contínuo, ocorreram diminuições nas arrecadações e oscilações monetárias. A falta de perspectivas para um acordo político pode ter ocasionado reduções nos investimentos, penalizando a população, mas preservando os gestores diante dos impositivos da norma.

\section{CONCLUSÕES}

Nos últimos vinte anos a temática das finanças municipais e os determinantes dos equilíbrios financeiros ganharam evidências. A pesquisa desenvolvida tem como foco a situação fiscal dos Municípios brasileiros entre os anos de 2002 e 2016, buscando esclarecer as interligações entre as receitas e as despesas públicas, com as atividades econômicas, o tamanho populacional e a mensuração dos respectivos impactos. Para tanto, na investigação do perfil arrecadador, foram apuradas as capacidades de geração de receitas próprias e dependências das transferências constitucionais, em contraponto com as análises dos gastos com pessoal, com impactos relevantes sobre a estruturação das contas públicas.

$\mathrm{Na}$ apuração do nível de riqueza dos Municípios, compreendendo que a arrecadação está diretamente associada com capacidade de gerar recursos, a variável PIB per capita foi o elemento principal para a dimensão econômica. A inclusão da participação da indústria, dos serviços e da agricultura, permitiu a contextualização das capacidades de agregação de valores, em conjunto com as definições dos perfis setoriais e das condições fiscais das prefeituras.

A relação negativa entre o QREF e as receitas próprias e de transferências, evidenciou que mesmo com crescimento dessas fontes pode haver déficit fiscal. Nesses casos, ganha relevância a atuação dos órgãos de controle e as manifestações dos cidadãos, na busca por eficácia.

O estabelecimento de um nível de gastos com pessoal acima do limite especificado pela LRF para o Poder Executivo, esteve associado à piora na gestão fiscal. O sinal do coeficiente negativo reforçou a necessidade de controle dos desembolsos, diante dos riscos de instabilidades financeiras, com impactos negativos sobre os investimentos e sobre a oferta de bens e serviços. Nesse caso, o estudo reforçou a percepção de que os mecanismos de controle previstos na norma devem ser considerados quando ocorrem aumentos com a folha de pagamento, acima dos limites confrontados pela Receita Corrente Líquida (RCL).

Diretamente, o coeficiente do PIB per capita apresentou significância estatística e sinal positivo, dando subsídios para a tese de que nas unidades mais ricas economicamente existiram maiores possibilidades da ocorrência de QREFs superiores. Esse resultado corrobora o entendimento de que o ambiente econômico é um elemento essencial para a situação fiscal. Com relação às atividades produtivas, os maiores QREFs foram detectados nos Municípios com participações mais amplas da agricultura e dos serviços, ficando aos gestores das cidades com perfil industrial a incumbência de detectar oportunidades para o aumento das arrecadações, conjuntamente com a adoção das melhores práticas de planejamentos estratégicos. 
Outra revelação do estudo apontou que o QREF tende a ser maior nas unidades mais populosas, o que se contrapõe com aos dados do IBGE que no de 2016, mostrou em suas estimativas que o país apresentou $88,17 \%$ dos Municípios, o equivale a aproximadamente 4.911 unidades, com menos de 50 mil habitantes, perfazendo um total de quase 65 milhões de pessoas (IBGE, 2017). Em contextos de desequilíbrios fiscais, poderá haver ofertas inadequadas de serviços e de bens públicos, forçando muitas vezes os deslocamentos dos cidadãos aos grandes centros, reduzindo assim a receita local. Como solução uma reforma tributária com descentralização da arrecadação, pode auxiliar os pequenos municípios.

Com o emprego de dummys em anos em que ocorreram variações reais negativas do PIB nacional, foi observado que em 2009 a situação fiscal foi pior na comparação com outros anos, revelando que os reflexos da crise iniciada em 2008, podem ter surpreendidos os prefeitos, uma vez que as despesas cresceram, enquanto que as receitas foram reduzidas. Nos anos de 2015 e de 2016, os resultados foram melhores e podem estar associados à cautela no aumento dos gastos públicos por parte dos gestores, diante dos efeitos da instabilidade política e dos cenários de incertezas econômicas.

Finalmente, cabe destacar que a pesquisa não contemplou outros três assuntos que interferem diretamente na gestão das prefeituras: não foram avaliados a qualidade e a quantidade dos bens e dos serviços públicos ofertados; os níveis de investimentos realizados, desconsiderando os montantes e os perfis das infraestruturas, com reflexos diretos na vida da população e na atratividade de recursos privados; e o grau de endividamento, sem ponderar os haveres futuros e que podem comprometer as disponibilidades dos tesouros municipais. 


\section{REFERÊNCIAS}

Afonso, J. R. R., \& Araújo, E. A. (2000). A capacidade de gasto dos municípios brasileiros: arrecadação própria e receita disponível. Cadernos de Finanças Públicas Esaf, 1, 19-30.

Afonso, J. R. R., Araujo, E. A., \& Nóbrega, M. A. R. (2010). O Imposto Predial e Territorial Urbano (IPTU) no Brasil. Um diagnóstico sobre o grau de aproveitamento do imposto como fonte de financiamento local (Working Paper). Cambridge, MA: Lincoln Institute of Land Policy.

Baltagi, B. H. (2001). Econometrics analysis of panel data (2a ed.). Chichester, UK: Wiley \& Sons.

Castillo, R. R. D. (2005). ¿Es sostenible la situación fiscal de las Provincias Argentinas? Revista de Economía y Estadística, 43(1), 123-165.

Chernick, H., \& Reschovsky, A. (2013). The fiscal health of U.S. cities (Working Paper). Cambridge, MA: Lincoln Institute of Land Policy.

Crove, J., \& Mattos, L. B. (2016). A situação fiscal e os ciclos políticos nos municípios brasileiros: uma análise a partir de dados em painel dinâmico espacial (XXI Prêmio do Tesouro Nacional). Recuperado de http://www.tesouro.fazenda. gov.br/documents/10180/558095/4o-lugarjulyana-covre-018.pdf/cca0e2eb-8335-43f7-b574$9 \mathrm{e} 7 \mathrm{ce} 7 \mathrm{c} 2 \mathrm{f} 55 \mathrm{~b}$

Cruz, C. F., Macedo, M. A. S., \& Sauerbronn, F. F. (2013). Responsabilidade fiscal de grandes municípios brasileiros: uma análise de suas características. Revista de Administração Pública, 47(6), 1375-1399.

Federação das Indústrias do Rio do Janeiro. (2016). Índice Firjan de Gestão Fiscal (IFGF). Recuperado de http://www.firjan.com.br/ifgf/

Fioravante, D. G., Pinheiro, M. M. S., \& Vieira, R. S. (2006). Lei de responsabilidade fiscal e finanças públicas municipais: impactos sobre despesas com pessoal e endividamento (Texto para discussão IPEA n. 1.223). Recuperado de http://www.ipea.gov.br/ portal/images/stories/PDFs/TDs/td_1223.pdf

Gerigk, W., \& Clemente, A. (2011). Influência da LRF sobre a gestão financeira: espaço de manobra dos municípios paranaenses extremamente pequenos.
Revista de Administração Contemporânea, 15(3), 513-537.

Gobetti, S. W., \& Klering, L. R. (2007). Índice de responsabilidade fiscal e qualidade de gestão: uma análise combinada baseada em indicadores de estados e municípios (XIII Prêmio do Tesouro Nacional). Recuperado de http://www.tesouro.fazenda.gov.br/ premio/Premio_TN/XIIpremio/lrf/1lrfXIIPTN/ indice_de_responsabilidade_fiscal.pdf

Hansen, S. W., Houlberg, K., \& Pedersen, L. H. (2014). Do municipal mergers improve fiscal outcomes? Scandinavian Political Studies, 37(2), 196-114.

He, Y. H. (2014). Fiscal stress in American municipalities: an analysis on the role of the State as it relates to municipal financial health (Public Affairs Capstones Collection, Paper 21). Recuperado de http://scholarworks.umb.edu/mspa_capstone/21

Hill, R. C., Griffiths, W. E., \& Judge, G. G. (1999). Econometria. São Paulo, SP: Saraiva.

Hsiao, C. (2003). Analysis of panel data (2a ed.). Nova York, NY: Cambridge University Press.

Instituto Brasileiro de Geografia e Estatística. (2017). Conta regionais e estimativas da população 20022016. Recuperado de: http://www2.sidra.ibge.gov.br

Klering, L. R., Kruel, A. J., \& Stranz, E. (2012). Os pequenos municípios do Brasil - uma análise a partir de índices de gestão. Análise, 23(1), 31-44.

Kohama, H. (1999). Balanços públicos: teoria e prática. São Paulo, SP: Atlas.

Lima, D. V., \& Castro, R. G. (2000). Contabilidade pública: integrando União, Estados e Municípios (Siafi e Siafem). São Paulo, SP: Atlas.

Magalhães, E. A. (2017). Gestão fiscal nos municípios brasileiros: uma análise das diferenças regionais (Tese de Doutorado). Universidade Federal de Viçosa, Viçosa, MG.

Mangas, M., Accotto, A. L., \& Martínez, C. R. (2016). La situación fiscal de las ciudades argentinas. Revista Iberoamericana de Estudios Municipales, 14(7), 151-184.

Massardi, W. O. \& Abrantes, L. A. (2014). Classificação dos municípios mineiros em relação à composição de suas receitas. Revista de Gestão, Finanças e Contabilidade, 4(1), 144-161. 
Musgrave, R. A. (1959). The theory of public finance. New York, NY: McGraw Hill.

Pinheiro, T. C. (2009). Hierarquia urbana e situação fiscal dos municípios brasileiros. Revista Brasileira de Estudos Regionais e Urbanos, 3(1), 107-127.

Quintela, M. C. A. (2011). Gasto público social dos estados brasileiros: um estudo sob a ótica da eficiência técnica (Tese de Doutorado). Universidade Federal de Viçosa, Viçosa, MG.

Reis, A. O. (2015). Descentralização e qualidade da gestão fiscal nos municípios mineiros: análise com dados em painel sob a perspectiva do ciclo eleitoral. (Dissertação de Mestrado). Universidade Federal de Viçosa, Viçosa, MG.

Riani, F. (2009). Economia do setor público: uma abordagem introdutória. Rio de Janeiro, RJ: LTC.

Ribeiro, F., \& Gerigk, W. (2016). O impacto da crise financeira internacional sobre os investimentos públicos municipais. Revista de Administração, Contabilidade e Economia, 15(1), 95-114.

Sakurai, S. N. (2014). Superavit e deficit fiscal dos municípios brasileiros: uma aplicação do modelo de viés de seleção em painel. Nova Economia, 24 (3), 517-540.

Secretaria do Tesouro Nacional. (2017). Sistema de informações contábeis e fiscais do setor público brasileiro. Recuperado de https://siconfi.tesouro. gov.br/siconfi/pages/public/consulta_finbra/ finbra_list.jsf

Silva, E. R. H. \& Porsse, A. A. (2015). Esforçotributário e interação estratégica dos governos municipais: uma análise com modelos geograficamente ponderados. Revista Econômica do Nordeste, 46(3), 115-130.

Silva, M. C. S., Tavares, A. L. T., Araujo, A. O., \& Silva, J. D. G. (2013). Análises de balanços públicos: quociente do resultado orçamentário do governo federal. 2000 - 2009. Revista Contabilidade Vista \& Revista, 24(3), 15-34.

Tristão, J. A. M. (2003). A Administração tributária dos municípios brasileiros: uma avaliação do desempenho da arrecadação (Tese de Doutorado). Escola de Administração de Empresas da Fundação Getúlio Vargas, São Paulo, SP.

Wooldridge, J. (2002). Econometric analysis of cross section and panel data. Cambridge, MA: MIT Press.

\section{Márcio Marconato}

https://orcid.org/0000-0001-9198-7610

Doutor em Economia; Professor colaborador da Universidade Estadual de Ponta Grossa.

E-mail: marconatoce@bol.com.br

\section{José Luiz Parré}

https://orcid.org/0000-0002-1569-8224

Doutor em Economia; Professor titular da Universidade Estadual de Maringá. E-mail: jlparre@uem.br

\section{Marcio Henrique Coelho}

https://orcid.org/0000-0002-2297-045X

Doutor em Engenharia Florestal; Professor titular da Universidade Estadual de Ponta Grossa.

E-mail: marhenco6@gmail.com 